\title{
ULTRASONIC PHASED ARRAY EVALUATION OF CONTROL ROD DRIVE MECHANISM (CRDM) NOZZLE INTERFERENCE FIT AND WELD REGION*
}

\author{
Anthony D. Cinson \\ Pacific Northwest National \\ Laboratory \\ Richland, WA USA
}

Royce A. Mathews

Pacific Northwest National Laboratory

Richland, WA USA

\author{
Susan L. Crawford \\ Pacific Northwest National \\ Laboratory \\ Richland, WA USA
}

\author{
Brady D. Hanson \\ Pacific Northwest National \\ Laboratory \\ Richland, WA USA
}

\author{
Paul J. MacFarlan \\ Pacific Northwest National \\ Laboratory \\ Richland, WA USA
}

\author{
Aaron A. Diaz \\ Pacific Northwest National \\ Laboratory \\ Richland, WA USA
}

\begin{abstract}
Ultrasonic phased array data were collected on a removedfrom-service CRDM nozzle specimen to assess a previously reported leak path. First a mock-up CRDM specimen was evaluated that contained two 0.076-mm (3.0-mil) interference fit regions formed from an actual Inconel CRDM tube and two 152.4-mm (6.0-in.) thick carbon steel blocks [1,2]. One interference fit region has a series of precision crafted electric discharge machining (EDM) notches at various lengths, widths, depths, and spatial separations for establishing probe sensitivity, resolution and calibration. The other interference fit has zones of boric acid (crystal form) spaced periodically between the tube and block to represent an actively leaking CRDM nozzle assembly in the field. Ultrasonic phased-array evaluations were conducted using an immersion 8-element annular $5.0-\mathrm{MHz}$ probe from the tube inner diameter (ID). A variety of focal laws were employed to evaluate the interference fit regions and J-grove weld, where applicable. Responses from the mock-up specimen were evaluated to determine detection limits and characterization ability as well as contrast the ultrasonic response differences with the presence of boric acid in the fit region. Nozzle 63, from the North Anna Unit-2 nuclear power plant, was evaluated to assess leakage path(s) and was destructively dismantled to allow a visual verification of the leak path(s).
\end{abstract}

\section{INTRODUCTION}

Research is being conducted for the U.S. Nuclear Regulatory Commission (NRC) at the Pacific Northwest National Laboratory (PNNL) to assess the effectiveness and reliability of advanced nondestructive examination (NDE) methods. Primary water stress corrosion cracking (PWSCC) in nickel-base alloy primary pressure boundary components may be a significant safety concern due to the potential for reactor pressure boundary leaks, the associated potential of boric acid corrosion of low alloy steels, and the development of flaws in piping or welds. These conditions, depending on the size and location of the flaws, could result in a significant loss-ofcoolant accident. Alloy 690 and its associated weld metals, Alloy 52 and 152, have been used in replacement pressurized water reactor (PWR) components to reduce PWSCC susceptibility[1,3]

\footnotetext{
*The United States Government retains, and by accepting the article for publication, the publisher acknowledges that the United States Government retains, a non-exclusive, paid-up, irrevocable, worldwide license to publish or reproduce the published form of this work, or allow others to do so, for United States Government purposes. The views expressed in this paper are solely those of the authors and are not necessarily those of the U.S. Nuclear Regulatory Commission.
} 
While more than 30 head replacements have occurred at operating PWRs, only a limited number of materials that have actually been in service are available for characterization and testing. In the 2001 refueling outage, some of the North Anna Unit-2 nozzles were repaired using Alloy 52/152 including Nozzles 63 and 51. In the 2002 refueling outage, 63 of 65 J-groove welds had flaw indications and cracking in 42 of these welds was severe enough to require repair. At that time, the utility decided to replace the reactor head. Previously, Electric Power Research Institute (EPRI) sponsored the removal and analysis of several nozzles. Currently, Nozzles 63, 51, and 10 are in storage at PNNL and are available for characterization studies and testing. Nozzle 63 will be available to the NRC to conduct independent tests. Some prior characterization of Nozzle 63 has been performed. Bare metal visual (BMV) examinations of Nozzle 63 were inconclusive and the nozzle was identified as masked indicating that a multitude of boric acid deposits from other sources surrounded the nozzle making it impossible to determine if Nozzle 63 was leaking [4]. However, a volumetric examination of Nozzle 63 revealed a probable leak path and indications on the outside diameter of the nozzle tube. Surface examinations of the J-groove weld identified axial indications.

Previous testing on material removed from the DavisBesse reactor head provided valuable information regarding crack growth rates of CRDM nozzle materials and welds. The Alloy 600 CRDM nozzles from Davis-Besse were determined to be highly susceptible to PWSCC whereas the Alloy 82/182 Jgroove weld metal had lower than average susceptibility based on measured PWSCC growth rates $[1,5]$. Unlike the DavisBesse CRDM nozzles, many of the cracks identified in the North Anna Unit-2 nozzle penetrations were located in the Alloy 82/182 J-groove weld and butter material. Some of the North Anna-2 CRDM nozzles including Nozzle 63 were weld repaired using an Alloy 52 weld overlay. A previous leak path assessment was conducted for Nozzle 63. It is of interest to conduct additional nondestructive assessments to characterize the leak path followed by destructive analysis and a comparison to the nondestructive examination.

\section{MOCKUP SPECIMEN (DESIGN)}

The CRDM mock-up calibration specimen consists of several components; mainly, the Inconel tube with flange, and two 6-in. carbon steel blocks. The design of this calibration specimen is to mimic the interference fit conditions between the Inconel tubing and the reactor vessel head (RVH) material as found in a PWR. The mock-up assembly employs similar materials and practices as utilized in the assembly of an actual $\mathrm{RVH}$; however, this mock-up will have two interference fit regions (Figure 1). One region, top block, contains EDM notches to establish an ultrasonic resolution and calibrated response from known voids. The second region, bottom block on this specimen, will have boric acid deposits strategically placed in the fit to simulate that a leakage path has been initiated and boric acid has been left behind. Due to safety concerns regarding specimen weight and center of mass, the flange end of the tube was be bolted to a larger plate for increased stability. Figure 1 graphically illustrates the assembled orientation of the specimen. Both interference fits will be created equally and in sequence under this assembly procedure.

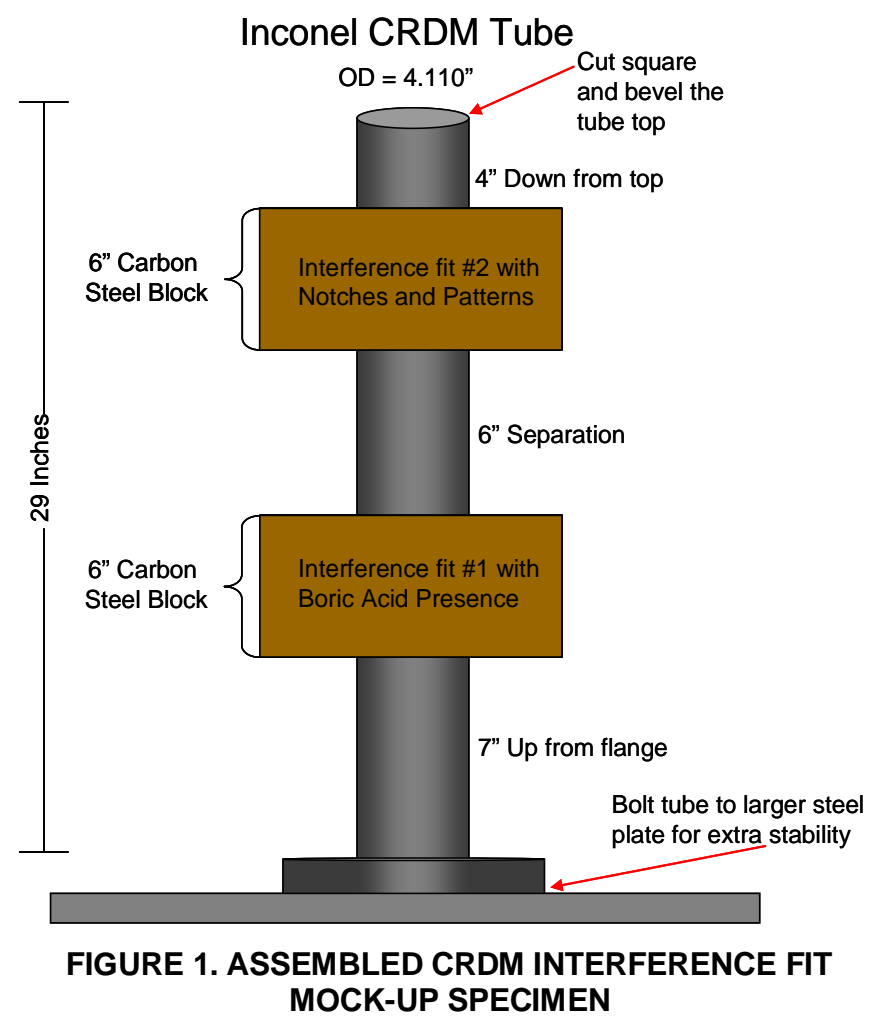

Boric Acid Presence: Interference fit \#1 contains boric acid deposits in the region where the Inconel tube meets the carbon steel block. The boric acid represents a likely leakage path as found in the field. The water inside an RVH contains a certain amount of boric acid that acts as a neutron absorber for controlling the nuclear reaction. Under pressure, some of this contaminated water has been known to leak past the CRDM seal weld at the wetted surface and into the interference fit region. With the extreme heat from the reactor, the water evaporates leaving behind the solid boric acid. During times of CRDM inspections, the presence of boric acid has been known to create a unique ultrasonic transmission and reflection pattern based upon the acid presence [1,4]. The mock-up is an attempt to simulate that very phenomenon.

The objective of this fit region was to create conditions where there are both regions of boric acid and where there was a lack of acid. Ideally, the contrast of the two regions in the ultrasonic data will reveal differences in ultrasonic transmission/reflection. The process of creating the simulated leakage paths with boric acid began with masking off regions on the Inconel tube outer diameter (OD) where boric acid was unwanted with masking tape. The boric acid was prepared for application by mixing a small amount of boric acid in solid form with a small amount of methanol. The two components 
were mixed into a paste with medium to high viscosity. The application of the acid involved spreading a thin and even coat of the paste with a compatible brush over the localized region on the OD of the tube between the masked off sections in a pattern as observed in Figure 2. Upon solidification of the boric acid, the masking tape was removed. Further, a snake-like pattern was scraped into a boric acid region as indicated with the blue line in Figure 2.

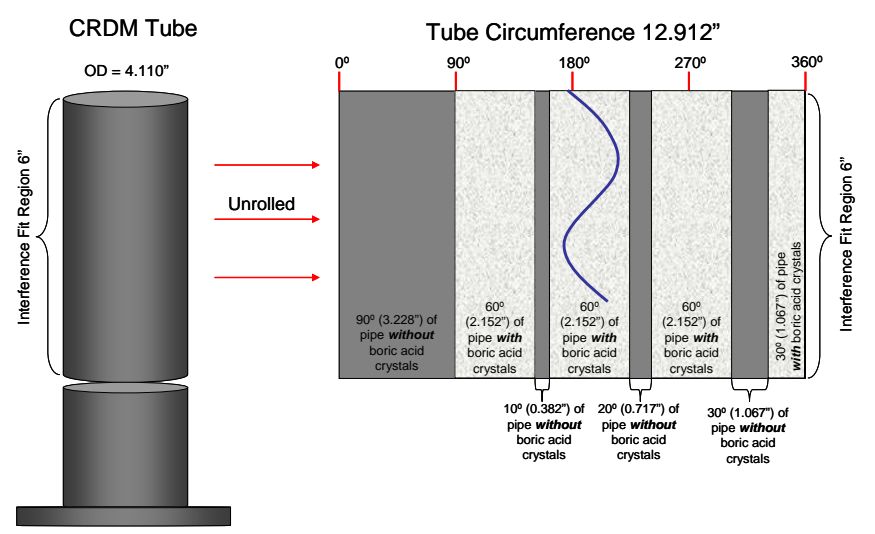

FIGURE 2. BORIC ACID PATTERN

EDM Notches and Patterns: The second interference fit contains various precision-crafted EDM notches (Figure 3) in the fit region. These notches were ultrasonically characterized to determine detection limits and image resolution.

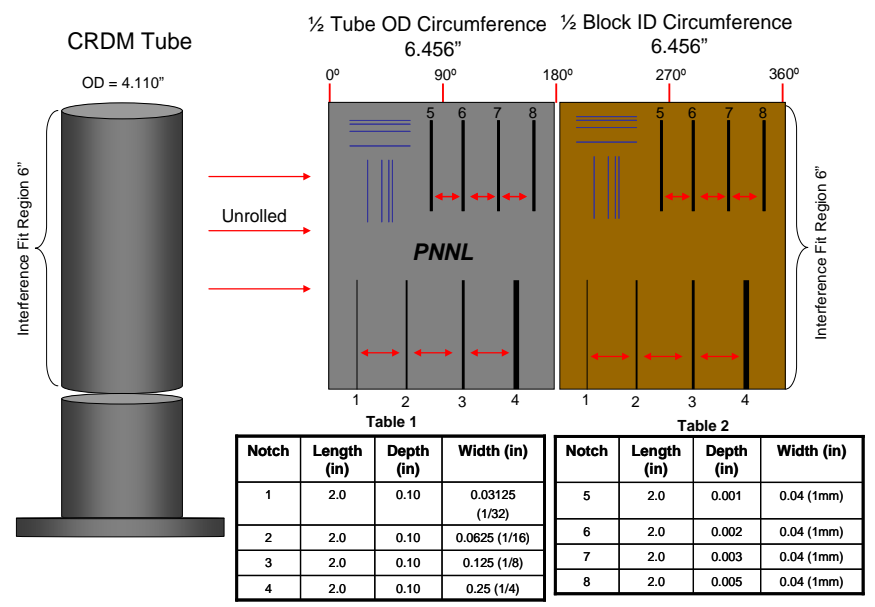

FIGURE 3. INTERFERENCE FIT \#2; NOTCH AND PATTERN DESIGN

This interference fit focuses on notches/patterns placed on the Inconel tube OD (silver colored region in Figure 3) as well as notches placed in the carbon steel block (represented by the brown/orange color in the figure). The first 180 degrees of the assembly has the notches cut into the tube OD and from 180 to 360 degrees has the notches cut into the carbon steel block ID. A theoretically determined spot size using the 5-MHz phasedarray (PA) probe at the interference fit region is $1.8 \mathrm{~mm}$
(0.071 in.) in both $\mathrm{x}$ and $\mathrm{y}$ directions (circumferential and axial directions). For reference, the theoretical wavelength $(\lambda)$ in the Inconel tube material at $5 \mathrm{MHz}$ is $1.1 \mathrm{~mm}$ (0.043 in.). The probe resolution in both the circumferential and axial directions was measured by acquiring data on a series of notches $2 \mathrm{~mm}$ wide $\times 2 \mathrm{~mm}$ deep $\times 25 \mathrm{~mm}$ long $(0.079$ in. $\times 0.079$ in. $\times$ 1.0 in.) that are spaced 2, 3, and $5 \mathrm{~mm}(0.079,0.12$, and 0.20 in.) apart (approximately 2, 3, and $5 \lambda$ ). One set of these notches is orientated circumferentially and the other is oriented axially represented by blue lines in Figure 3. To measure detection sensitivity, axial notches $1-4$ are placed equidistant from each other and have a constant depth while the widths vary from 0.7938 to $6.35 \mathrm{~mm}$ (0.03125 to 0.25 in.) wide, simulating potential leakage paths. The third set of notches is for depth sensitivity determination and is also placed axially and equidistant from each other. These are notches 5-8 and will have consistent lengths and widths but vary in depth. These three sets of notches do not overlap, but rather remain separated so that ultrasonic observations can be made independently for resolution (the ability to resolve two closely spaced indications) and width and depth sensitivity. The acronym 'PNNL' is also notched on the OD of the tube for uniqueness and will provide an indication of off-axis sensitivity.

\section{Mockup Specimen (Assembly)}

The assembly of this mock-up specimen involved temporarily shrinking the Inconel tube to accept the carbon steel blocks that have been accurately and precisely machined with a hole that is 3 mils smaller than the OD of the Inconel tube when all components are at a room temperature of $22^{\circ} \mathrm{C}$ $\left(72^{\circ} \mathrm{F}\right)$. This created an interference fit of 3 mils after all components returned to room temperature [2].

To shrink the Inconel tube, liquid nitrogen (LN) was used to cool the tube component to approximately $-210^{\circ} \mathrm{C}\left(-346^{\circ} \mathrm{F}\right)$. As the tube rested vertically in a stainless steel secondary containment trough, LN was added in the Inconel tube until full. Full was defined as $101.6 \mathrm{~mm}$ (4 in.) below the top to prevent boil over. The LN was contained solely within the tube. Prior to attaching the flange end of the tube to the foot plate as pictured in Figure 2, a permanent end cap has been seal welded at the flange end of the tube to prevent leaking of any liquid. Once the tube cavity is full of LN, the OD of the tube was monitored until the maximum shrinkage level was achieved. A 0.234-mm (0.0092-in.) shrinkage value was theoretically determined based on a $104.14 \mathrm{~mm}$ (4.1-in.) length of Inconel 718, as described next.

The expected amount of thermal reduction was calculated for the nozzle and then later experimentally measured. Thermal expansion coefficients are generally given in tabular form for different materials over a given temperature range. These table values assume a linear relationship over a limited temperature range. Cryogenic material properties are needed for the temperatures used in forming the interference fit. Two reference papers discuss material properties of metal alloys at cryogenic temperatures. Inconel 718 was one of the material studied and will represent the nozzle material for our calculated material 
shrinkage estimates. To form the interference fit, the nozzle will be taken from room temperature, $293^{\circ} \mathrm{K}$, to the temperature of liquid nitrogen, $77.2^{\circ} \mathrm{K}$. Clark [6] measured the thermal expansion coefficients from liquid hydrogen temperature to room temperature, $20^{\circ} \mathrm{K}$ to $293^{\circ} \mathrm{K}$, in 10 or 20 degree steps for different metallic alloys. Results are presented in tabular form for the expansion relative to room temperature. From the table for Inconel 718 at $80^{\circ} \mathrm{K}$ :

$$
223=[(\mathrm{L} 293-\mathrm{L} 80) / \mathrm{L} 293] \times 105
$$

expansion relative to room temperature

The calculated expansion from Eq. (1) gives a shrinkage value of $0.232 \mathrm{~mm}$ (0.00914 in.) for a $104.14 \mathrm{~mm}$ (4.1in.) -long section of Inconel 718 material.

Marquardt [7] models the material properties over a large temperature range ( 4 to $300^{\circ} \mathrm{K}$ ) with a polynomial or a logarithmic polynomial equation. An equation for the integrated linear thermal expansion or change in length is given as:

$$
(\mathrm{LT}-\mathrm{L} 293) / \mathrm{L} 293=(\mathrm{a}+\mathrm{bT}+\mathrm{cT} 2+\mathrm{dT} 3+\mathrm{eT} 4) \times 10^{-5}
$$

The coefficients for 718 Inconel are listed as:

$$
\begin{array}{ll}
\mathrm{a}=-2.366 \mathrm{E}+02 & \mathrm{~d}=-7.164 \mathrm{E}-06 \\
\mathrm{~b}=-2.218 \mathrm{E}-01 & \mathrm{e}=0 \\
\mathrm{c}=5.601 \mathrm{E}-03 &
\end{array}
$$

From this equation the expansion relative to room temperature for a temperature of $77^{\circ} \mathrm{K}$ is calculated to be $223.74 \times 10^{-5}$. Applying this value to a $104.14 \mathrm{~mm}$ (4.1 in.) length of Inconel produces a shrinkage value of $0.233 \mathrm{~mm}$ (0.00917 in.) This result very closely matches the result from Eq. (1) given above.

\section{Ultrasonic Phased Array Probe}

The specimens were examined with a pulse-echo (PE) longitudinal phased-array probe with a center frequency of $5 \mathrm{MHz}$. The PA probe was designed in a 1-D annular configuration using eight elements. The probe contains elements in a Fresnel radius pattern starting with a radius of $3 \mathrm{~mm}$ (0.12 in) up to the final element radius of $9.72 \mathrm{~mm}(0.38$ in). Thus, the total aperture is $296.81 \mathrm{~mm}^{2}\left(0.46 \mathrm{in}^{2}\right)$. The probe exhibits a $72 \%$ bandwidth at -6 decibels (dB). This particular design was chosen for enhanced depth focusing capabilities. Its beam forming capabilities have been modeled to show a satisfactory notification of the interference fit region of interest as well as the ability to propagate a uniform ultrasonic beam deep into the weld region.

\section{FOCAL LAW DEVELOPMENT}

Before a PA probe can be used to perform an examination, a set of focal laws must be produced to control the firing of individual elements which in turn form a beam. The focal laws are inputs to the Ultravision control software, which determines specific elements to excite at specific times to allow for proper beam-forming in the material to be examined. The focal laws also contain details about the angles being generated, the focal point of the sound field, the delays associated with the wedge and electronics, and the orientation of the probe. PNNL uses a software package contained in the Ultravision 1.2R4 software program for producing focal laws known as the "ZETEC Advanced Focal Law Calculator." The software package performs two functions: (1) focal law generation and (2) simulation of the ultrasonic field produced by the probe when using the generated laws. The user enters the physical information about the PA probe, such as the number of elements, the sizes of the elements, and the wedge information, such as the wedge angle and the wedge size, into the program. The desired angles and focal distances are then entered, and the software generates the needed delays for each element to produce the desired beam steering and focusing in the material. The software beam simulation produces a simple image of the probe on the wedge, ray-tracing to show the focal depth and steering desired, and density mapping to enable the viewer to see how well the sound field responds for a particular angle and whether grating lobes exist that may be detrimental to the examination. Figure 4 shows an example of the ray tracing for a probe on the left with the sound field density mapping on the right for a particular depth. It should be noted that this simulation is performed in isotropic material; that is, the velocity of sound is maintained throughout any angle for a particular wave mode.

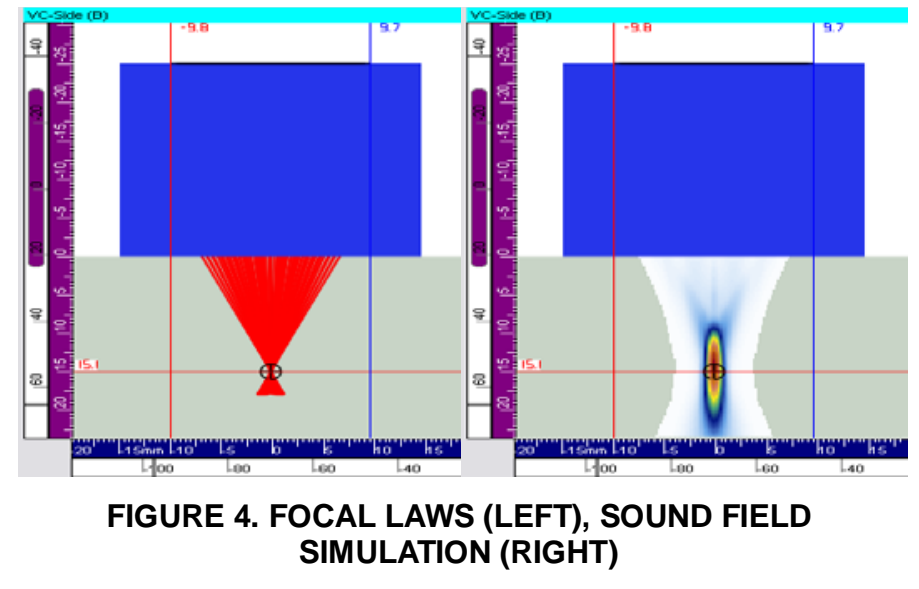

\section{ULTRASONIC PHASED ARRAY CONFIGURATION}

Set-up and laboratory configuration for PA-ultrasonic testing (UT) data acquisition on the mockup specimen and Nozzle 63 required the use of a custom slave-encoded scanner to be mounted on the specimen. The scanner has two stepper motors that control the axes of movement; circumferentially around the specimen and vertical in the axial direction of the specimen. Attached to the motor shafts are slave encoders that provide circumferential and axial position information to the PA electronics. The scanner was attached to the tube by sliding the scanner over the tube and the three set screws were tightened. This provided easy manipulation for fine-tuning of the alignment of the scanner for optimum phased-array data collection. The setup is shown in Figure 5 with the scanner on 
the calibration specimen. The probe was mounted on an extension arm that is adjustable along the pipe axis for easy adjustment to scan the region of interest.

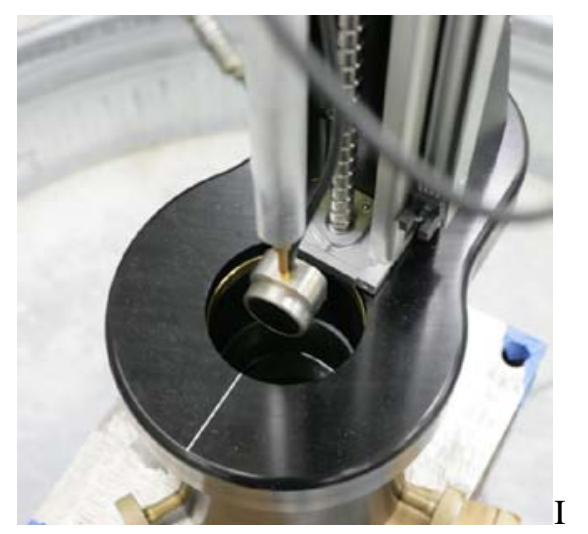

\section{FIGURE 5. SCANNER ON CALIBRATION SPECIMEN}

Water filled the tube to establish adequate acoustic coupling between the probe and the specimen ID surface. Data acquisition was accomplished using the ZETEC Tomoscan III system. This commercially available system is equipped to accommodate a maximum of 64 channels from PA probes and requires the use of Ultravision 1.2R4 software. Its frequency pulsing electronics will drive probes in the $0.5-20 \mathrm{MHz}$ range. Phased-array data were acquired over a range of inspection depths from $1-15 \mathrm{~mm}\left(0.039-0.59 \mathrm{in}\right.$.) at a normal or $0^{\circ}$ angle of inspection. Raster data were acquired at 0.25 degree in the scan and $0.5-\mathrm{mm}$ (0.019 in.) increment in the index on the calibration specimen and 0.5 degree in the scan and $0.5-\mathrm{mm}$ (0.019 in.) increment in the index for Nozzle 63. The scan axis was defined as the circumferential direction around the tube and the index defined as the axial travel up or down the tube.

\section{PHASED ARAY DATA AND ANALYSIS (CALIBRATION SPECIMEN)}

Data were acquired on the calibration mockup assembly with the ultrasonic PA probe. For reference, a drawing of the machined notches is displayed in Figure 6. The notch pattern was machined into the ID of the carbon steel material in the 180 to 360 degree range and in the Inconel tube OD over the 0 to 180 degree range. The axial resolution notches are in the upper left in the figure. Just below are the circumferential resolution notches. The upper right contains notches that vary in depth and the lower notches vary in width.

The Inconel tube notched area was scanned over approximately a 0 to 170 degree range in the circumferential direction and 10 to $180 \mathrm{~mm}$ (0.39 to 7.09 in.) in the axial direction with the data image shown in Figure 7. This top view or C-scan image displays the resolution notches in the upper left portion of the image. The variable depth and width notches are also seen as well as the "PNNL" letters.

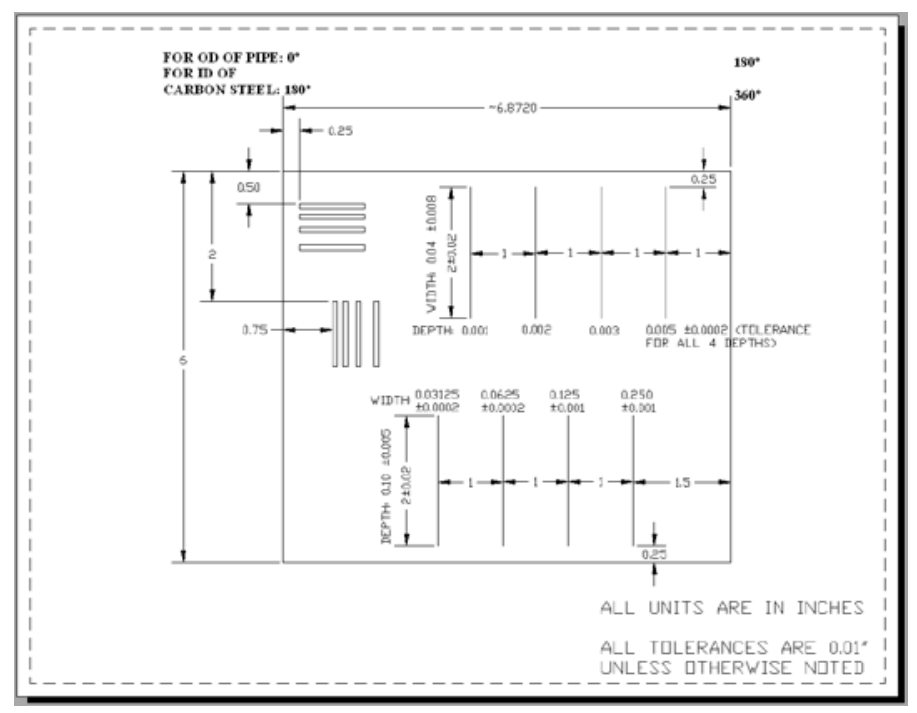

FIGURE 6. NOTCH PATTERN IN THE CRDM CALIBRATION MOCKUP SPECIMEN, UPPER INTERFERENCE FIT

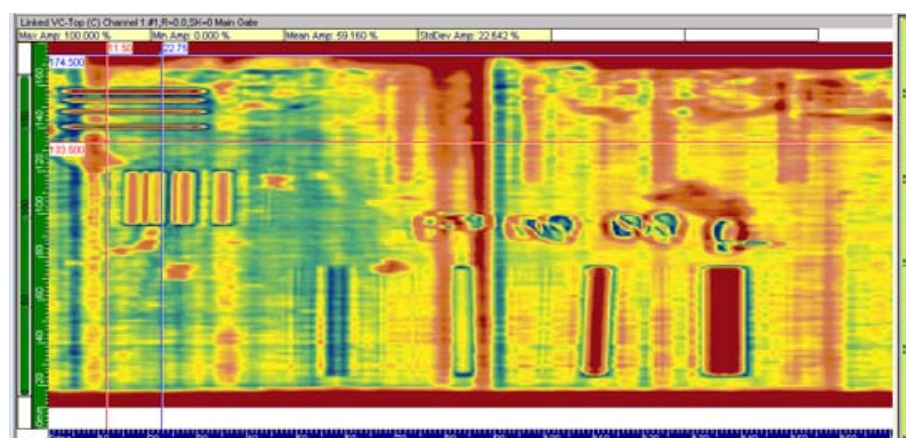

FIGURE 7. TOP VIEW, PLAN VIEW OR C-SCAN ULTRASONIC IMAGE OF THE UPPER INTERFERENCE FIT REGION CONTAINING CALIBRATION NOTCHES IN THE INCONELTUBE

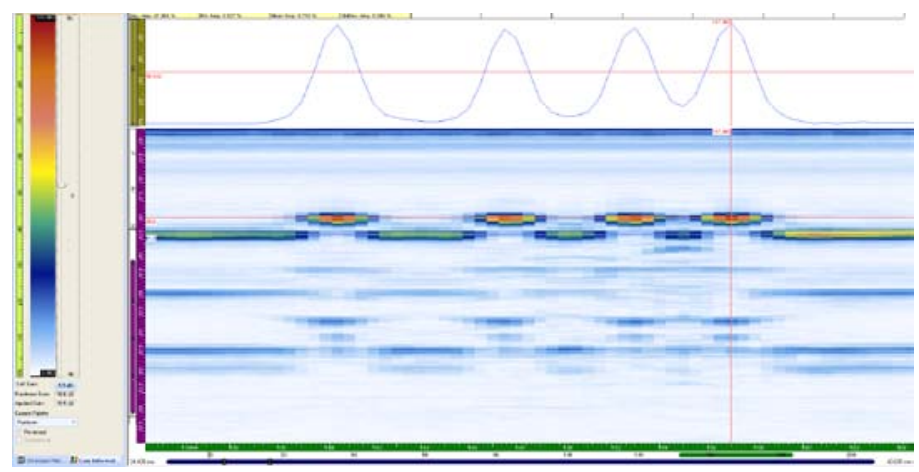

FIGURE 8. D-SCAN END VIEW OF THE AXIAL RESOLUTION NOTCHES IN THE INCONEL TUBE

The axial resolution notches are gated or selected for analysis. An enlarged end view depicted in Figure 8 is used to measure the center-to-center spacing of the notches. From this view an "echo dynamic" line or profile is drawn through the upper part of the notches' responses and plotted at the top of the 
image. The notch widths left to right as measured at the half amplitude points are 2, 2, 2.5, and $2.5 \mathrm{~mm}(0.08,0.08,0.10$, and $0.10 \mathrm{in}$.). The true widths are $2.03 \mathrm{~mm}$ ( $0.80 \mathrm{in}$.) for all four notches. Notch depths are measured at $2 \mathrm{~mm}$, which agrees with the true depth of $2.03 \mathrm{~mm}$ (0.08 in.) for all four notches. Finally, the notches are separated from each other providing an indication of probe resolution in the axial direction. In this set of notches, the center-to-center true-state separation is 7.11, 5.08 , and $4.06 \mathrm{~mm}(0.28,0.20$, and $0.16 \mathrm{in}$.). The corresponding measurements are $7.0,5.5$, and $4.0 \mathrm{~mm}(0.28,0.22$, and 0.16 in.) indicating a better than $4.0 \mathrm{~mm}$ (0.16 in.) axial resolution.

The circumferential resolution notch set is shown in Figure 9. Notice that the closely spaced two notches on the left are overlapping but they are still resolvable. Peak-to-peak measurement values produced a separation of $4.6,4.8$, and 7.3 $\mathrm{mm}(0.18,0.19$, and $0.29 \mathrm{in}$.). Again, the true-state separation values are $4.06,5.08$, and $7.11 \mathrm{~mm}(0.16,0.22$, and $0.28 \mathrm{in}$.) showing that the circumferential probe resolution is approximately $4 \mathrm{~mm}(0.16$ in.) at best.

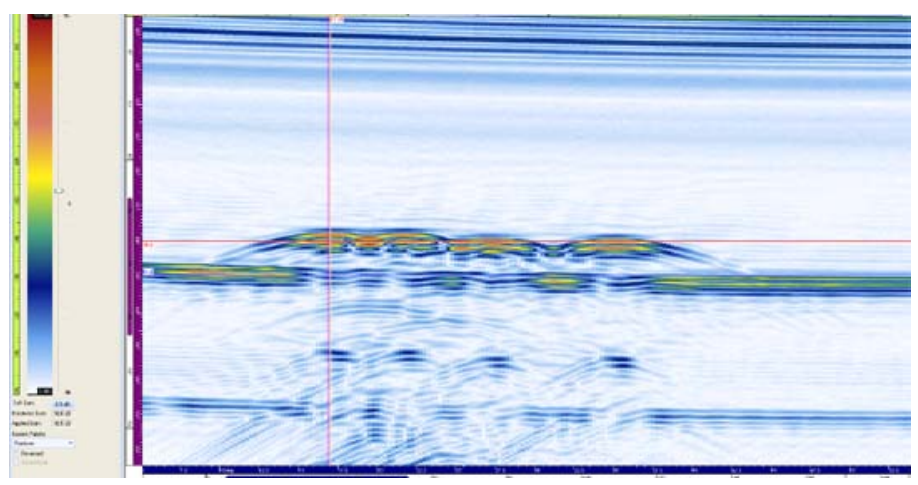

FIGURE 9. B-SCAN SIDE VIEW OF THE CIRCUMFERENTIAL RESOLUTION NOTCHES IN THE INCONEL TUBE

The set of notches in the upper right portion of the scanned image (Figure 7) vary in depth. The center-to-center spacing of the flaws measures 23.84, 24.29, and $23.61 \mathrm{~mm}(0.94,0.96$, $0.93 \mathrm{in}$.) whereas the true spacing is $25.4 \mathrm{~mm}$ (1.0 in.). Flaw depths were not measurable. Higher frequency may be needed to resolve the depths of these notches.

The final set of notches contained width variations and are shown in Figures 10 and 11. These flaws were measured with depths of 2.2, 2.5, 2.7, and $2.9 \mathrm{~mm}(0.09,0.10,0.11$, and 0.11 in.), left to right in the image, while true state is $2.53 \mathrm{~mm}(0.10$ in.) for all notches. The widths of the flaws were measured in two ways. The first used the width of the upper part of the flaw response and the second used the width of the loss of back-wall signal. The loss of back-wall signal was more accurate with empirical width values of 2.52, 3.21, 3.90, and $7.56 \mathrm{~mm}$. True state is $0.79,1.59,3.18$ and $6.35 \mathrm{~mm}(0.03,0.06,0.13$, and 0.25 in.). When measured from the second ultrasonic back-wall echo, the loss of signal measurements give notch widths of $0.917,2.521,3.896$, and $6.417 \mathrm{~mm}(0.036,0.099,0.153$, and 0.253 in.), which are better representations of true state.

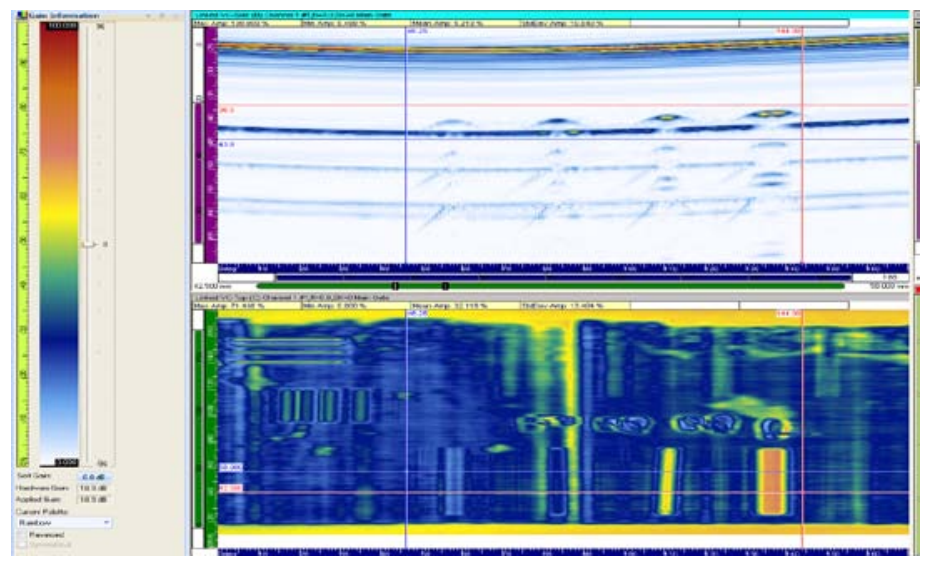

\section{FIGURE 10. B-SCAN SIDE VIEW ON TOP AND C-SCAN PLAN VIEW ON BOTTOM OF THE WIDTH VARYING NOTCHES IN THE INCONEL TUBE}

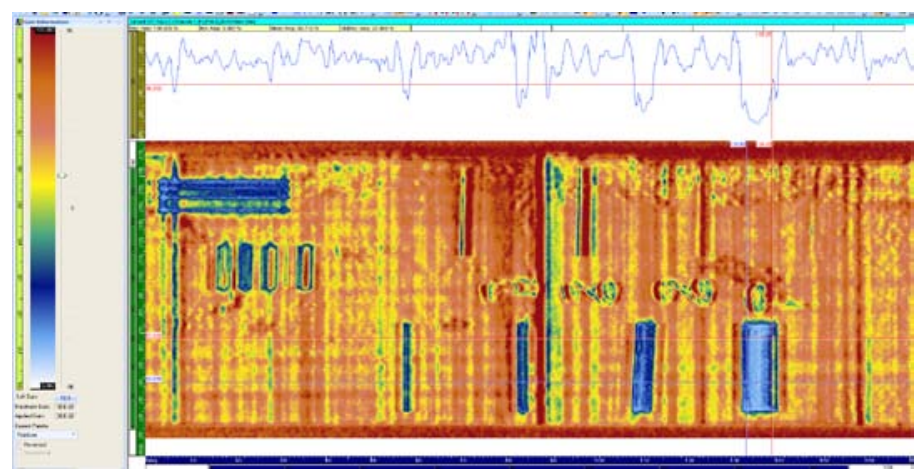

\section{FIGURE 11. C-SCAN TOP VIEW OF THE WIDTH VARYING NOTCHES IN THE INCONEL TUBE WITH THE LOSS OF SIGNAL IN THE BACK WALL ECHO GATED}

The 180-360 degree portion of the upper fit region contains notches in the carbon steel; therefore on the far side of the interference fit. Because the interference fit is not uniform, the notch responses are degraded as evident in Figure 12.

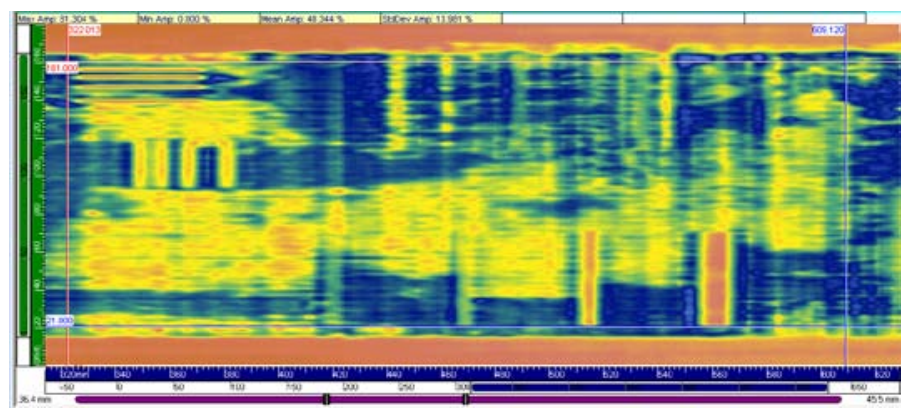

FIGURE 12. C-SCAN PLAN VIEW OF THE NOTCHES IN THE CARBON STEEL

The axial resolution notches are resolved (Figure 13) but the lower notch is on the edge of a high amplitude region. The center to center measurements are 3.90, 4.58, and $6.88 \mathrm{~mm}$ 
$(0.15,0.18$, and 0.27 in.) with a true state of $4.1,5.1$, and 7.1 $\mathrm{mm}(0.16,0.20$, and 0.28 in.).

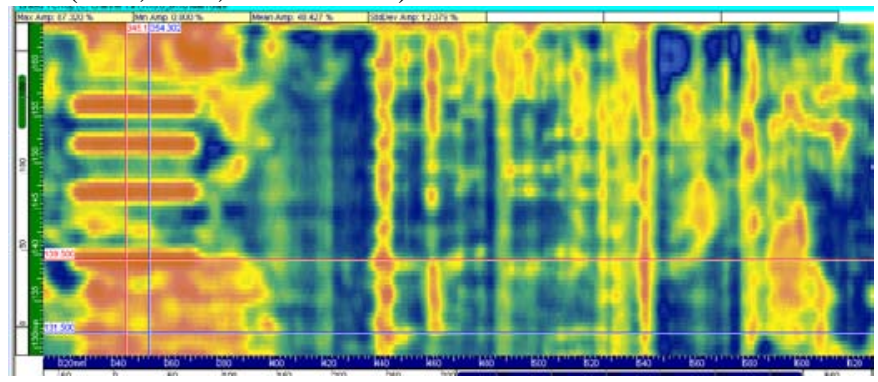

FIGURE 13. C-SCAN PLAN VIEW OF THE AXIAL RESOLUTION NOTCHES IN CARBON STEEL, ON THE LEFT.

The circumferential resolution notch pattern is better seen in the second echo as shown in Figure 14. Measurements on the center to center spacing are $3.90,5.04$, and $7.56 \mathrm{~mm}(0.15$, 0.20 , and $0.30 \mathrm{in}$.) with true state at $4.1,5.1$, and $7.1 \mathrm{~mm}(0.16$, 0.20 , and 0.28 in.).

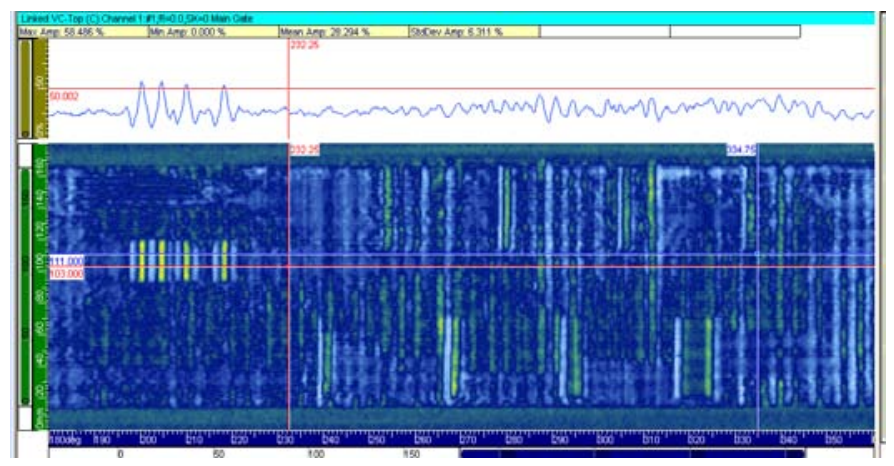

FIGURE 14. C-SCAN PLAN VIEW OF THE CIRCUMFERENTIAL RESOLUTION NOTCHES IN CARBON STEEL, ON THE LEFT. THIS IMAGE WAS ACQUIRED FROM THE SECOND ULTRASONIC ECHO.

The depth notches are detected but depths are not measurable. First and second echo images are shown in Figures 15 and 16, respectively. Center to center spacing is measured at 23.84, 23.84 and $24.98 \mathrm{~mm}(0.94,0.94$, and 0.98 in.) with a true state of $25.4 \mathrm{~mm}$ (1 in.) for all notches.

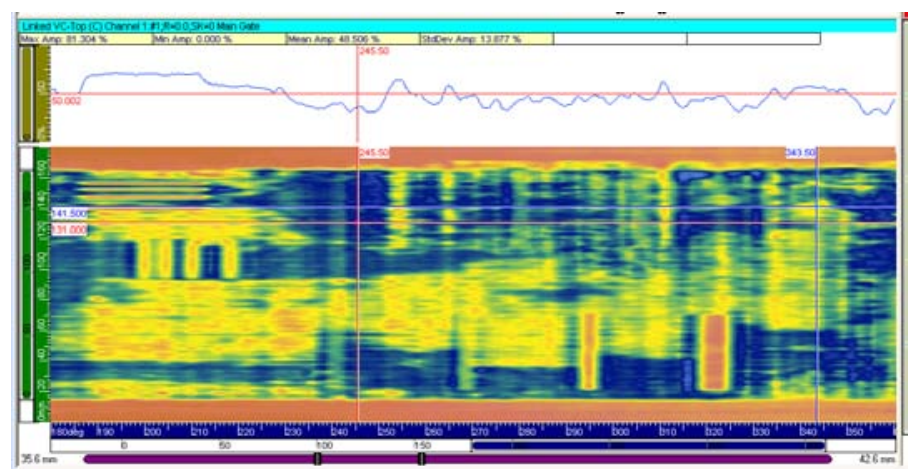

FIGURE 15. C-SCAN PLAN VIEW OF THE DEPTH NOTCHES IN CARBON STEEL, ON THE UPPER RIGHT. THIS IMAGE WAS ACQUIRED FROM THE FIRST ULTRASONIC ECHO.

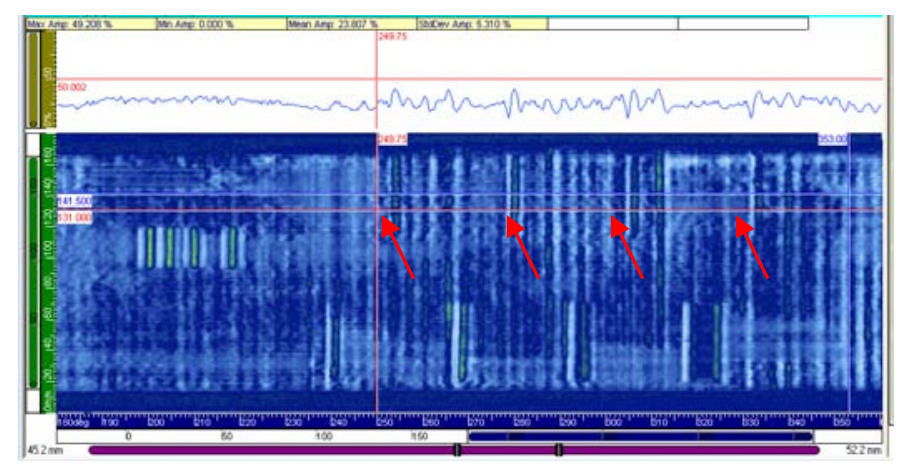

FIGURE 16. C-SCAN PLAN VIEW OF THE DEPTH NOTCHES IN CARBON STEEL, ON THE UPPER RIGHT. THIS IMAGE WAS ACQUIRED FROM THE SECOND ULTRASONIC ECHO.

The set of notches with variable widths is shown in Figure 17 at the bottom of the image. Measurements on notch widths are not reported here, but four notches are detected.

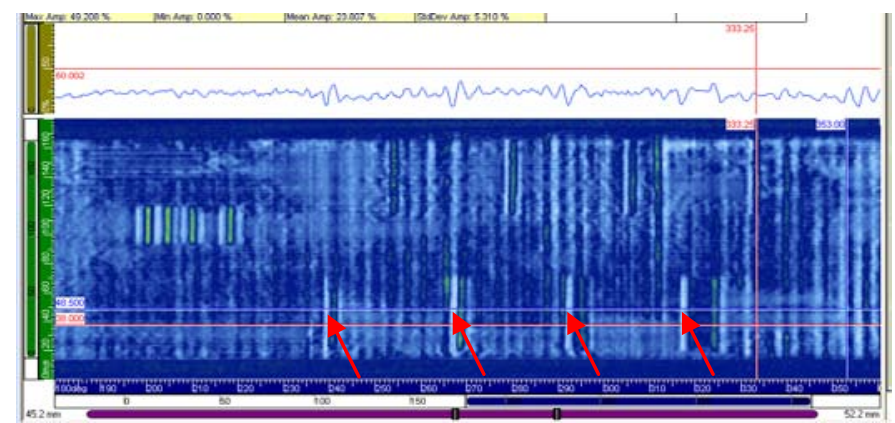

FIGURE 17. C-SCAN PLAN VIEW OF THE WIDTH NOTCHES IN CARBON STEEL, ON THE BOTTOM. THIS IMAGE WAS ACQUIRED FROM THE SECOND ULTRASONIC ECHO.

The images from the lower interference fit region containing boric acid deposits are displayed in Figure 18-20. Note: during assembly of the lower fit, the carbon block came to rest at a location that only covers half of the applied boric acid regions. The first two images represent the 60 to 240 degree region showing respectively the first and second echoes 
from the interference fit region. The third image represents the 240-420 degree region as captured by the first echo.

In addition to characterizing the notch response data for probe spatial resolution and detection capability an analysis of the acoustic response from the different regions was performed based on the reflected signal strength. The three regions considered were the interference fit region, the boric acid region and the tube region outside of the interference fit area. Measurements were acquired from areas in the normalized images that represented these three regions.

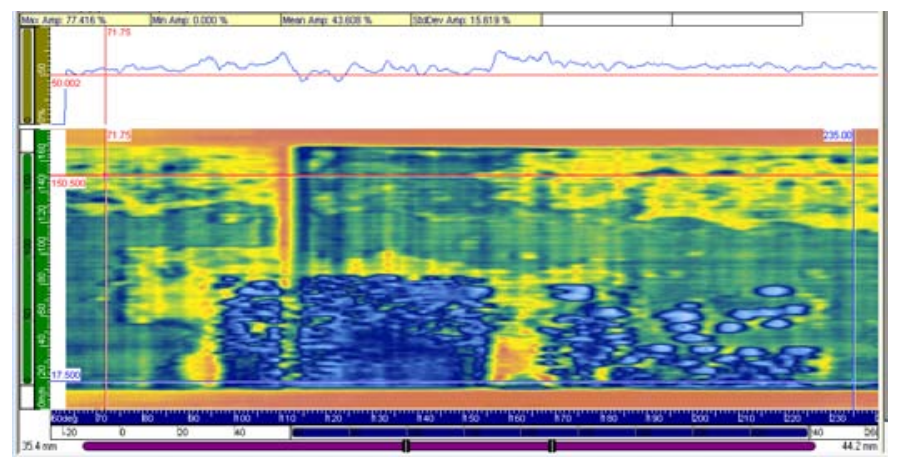

FIGURE 18. C-SCAN PLAN VIEW OF THE BORIC ACID DEPOSITS IN THE LOWER INTERFERENCE FIT REGION. THE HORIZONTAL AXIS REPRESENTS THE CIRCUMFERENTIAL RANGE OF 60 - 240 DEGREES. THIS IMAGE IS FROM THE FIRST ULTRASONIC ECHO.

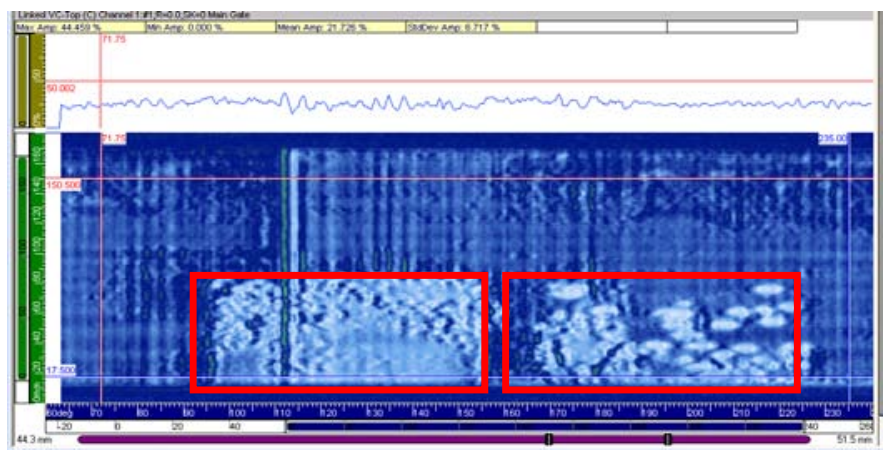

FIGURE 19. C-SCAN PLAN VIEW OF THE BORIC ACID DEPOSITS IN THE LOWER INTERFERENCE FIT REGION. THE HORIZONTAL AXIS REPRESENTS THE CIRCUMFERENTIAL RANGE OF 60 - 240 DEGREES. THIS IMAGE IS FROM THE SECOND ULTRASONIC ECHO.

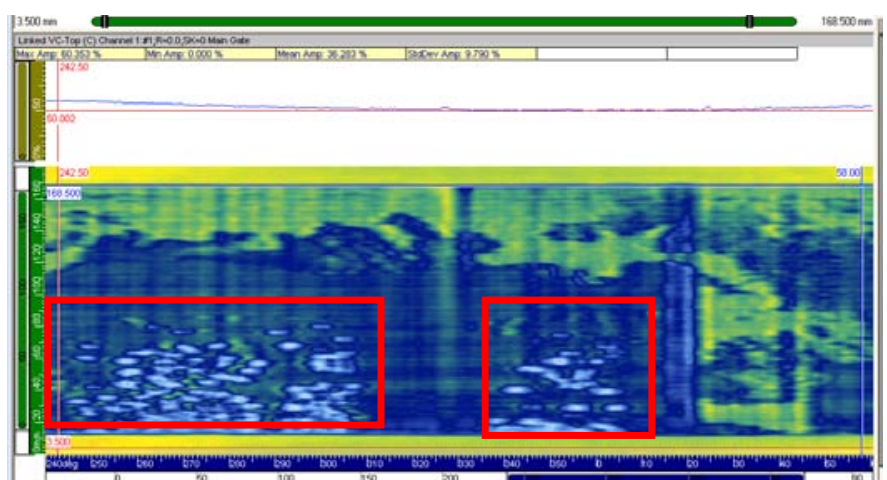

FIGURE 20. C-SCAN PLAN VIEW OF THE BORIC ACID DEPOSITS IN THE LOWER INTERFERENCE FIT REGION. THE HORIZONTAL AXIS REPRESENTS THE CIRCUMFERENTIAL RANGE OF 240 - 420 DEGREES. THIS IMAGE IS FROM THE FIRST ULTRASONIC ECHO.

The mean responses from the fit region are in the $25-45 \%$ of full screen amplitude range. This wide range is due to the variability in the fit itself. Some regions are tighter than others, giving a lower reflected amplitude and more transmitted energy. Other regions of the fit show higher reflected energy, thus less transmitted energy. Machining marks are evident and also lead to response variability.

The mean responses of the boric acid regions are in the 20 $25 \%$ range of full screen height. This shows more energy transmitted through the interference fit region with the presence of boric acid than in the regions without boric acid. The boric acid crystals fill gaps in the fit and efficiently couple the ultrasonic energy into the carbon steel material.

Finally the mean responses of the tube region are 50-60\% of full screen height, demonstrating greater reflectance of energy at the outside tube surface to air interface. This is a good base line for the Inconel tube to air interface reflectivity amplitude level.

This mockup data show that the three regions, interference fit, boric acid in the interference fit and tube, are separable based on the mean ultrasonic response. The Nozzle 63 responses will likely be somewhat different but the mockup data has provided a basis for response differentiation. This coupled with a basic review of the data for a leakage path pattern in the data images will enhance the detection of the previously reported leakage path in Nozzle 63.

\section{PHASED ARAY DATA AND ANALYSIS (NOZZLE 63)}

The phased array data acquisition system and scanner was moved to the facility housing the Nozzle 63. A controlled environment was constructed around the nozzle to prevent radioactive contamination of the phased array electronics (Figure 21). The scanner and probe will become contaminated during this process and either be stored appropriately, or disposed of as radioactive waste. 


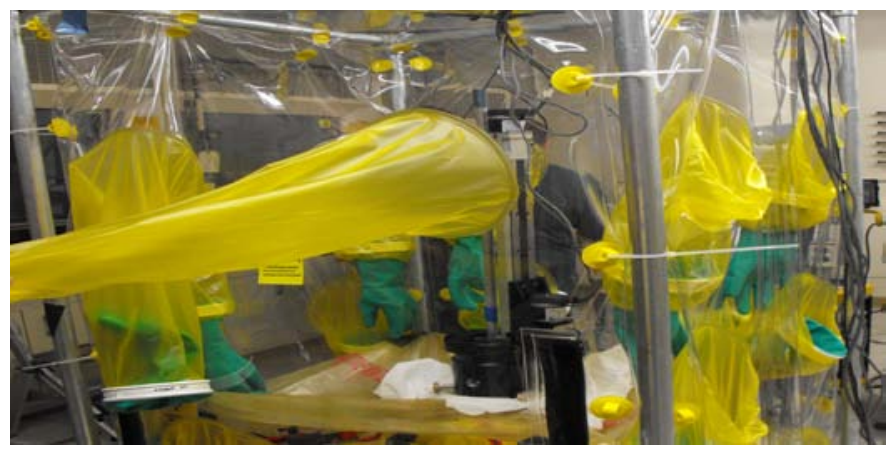

FIGURE 21. NOZZLE 63 SETUP

Scanning was conducted on Nozzle 63 using the same setup and data acquisition methods used for the calibration specimen. First, a coarse scan was conducted with a circumferential resolution of 0.5 degrees and $4 \mathrm{~mm}$ ( $0.15 \mathrm{in}$.) in the axial (index) axis over the scan regions of -94 to 94 degrees and 86 to 274 degrees circumferentially. The scan index ranged from 0 to $360 \mathrm{~mm}$ (0 to $14.2 \mathrm{in}$.). The coarse scans allowed the regions of interest to be bounded for higher resolution scanning. Features such as the J-grove seal weld and the top of the interference fit were easily recognizable in the coarse scan data. Bubbles on the ID tube surface were identified and removed prior to high resolution scanning.

High resolution scans were conducted with 0.5 degree resolution in the scan and $0.5 \mathrm{~mm}(0.020 \mathrm{in}$.) resolution in the index over the scan regions of -94 to 94 degrees and 86 to 274 degrees. Both scans extended in the axial direction a distance of 0 to $360 \mathrm{~mm}$ (0 to $14.2 \mathrm{in}$.). Each high resolution scan was conducted twice to measure repeatability. Overlapping the two scanned regions, a constructed 360 degree scan of the interference fit region is shown in Figure 22 and shows the Jgrove weld and fit regions of interest. The J-grove weld region is identified as the white to light-blue oscillating band region in the lower third of the figure. Again, the white and light-blue regions signify regions of ultrasonic transmission; a welded region should have the highest indication of ultrasonic transmission. Within the weld region, several volumetric reflection indications are present; likely they are embedded weld flaws created during the seal welding process. The interference fit region begins just above the J-groove weld and ends at the black line in the upper third of the image. This line has been externally added to bound the fit region. Regions above the fit and below the weld are considered to be tube only reflections.

The investigation of the interference fit region on nozzle 63 shows a variety of responses. Some responses are strong in reflection amplitude while others indicate ultrasonic transmission. Pattern recognition analysis of the strong reflection indications shows at least one visible path connecting the weld to the top of the fit region. This leak path originates at approximately the 180 degree location marked by the black arrow. The lower amplitude cluster regions near the leak path (boxed) could indicate the presence of boric acid in the fit as shown in the calibrations specimen. During active leaking, it is possible to deposit boric acid in the vicinity of the leak zone.

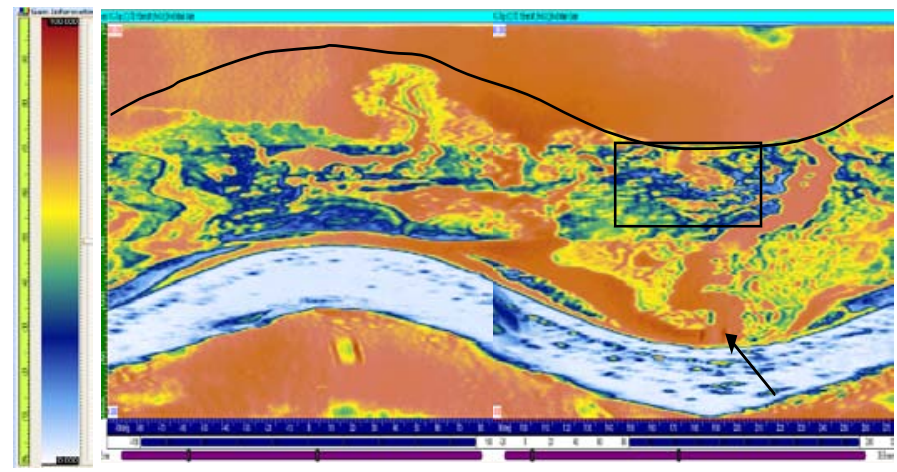

FIGURE 22. CONSTRUCTED 360 DEGREE SCAN

\section{CONCLUSION}

Ultrasonic phased array inspection using an annular phased array probe is an effective NDE technique for identifying and assessing leak paths contained within the interference fit region of the CRDM tube and the RVH. Through the testing of the mockup calibration specimen this study has shown the sensitivity of the phased array approach for anomaly detection. The resolution was tested for detection of shallow voids and spaced notches as well as the difference in reflection/ transmission percentages in the case of boric acid trapped in the fit zone. Based on the phased array data a potential leak path was identified in Nozzle 63 at approximately the 180 degree point. Future destructive testing will confirm this claim along with others regarding the presence of boric acid in the fit.

\section{ACKNOWLEDGMENTS}

The work reported here was sponsored by the U.S. Nuclear Regulatory Commission and conducted under NRC Job Code Number N6783. Greg Oberson is the NRC program monitor and Darrell Dunn is the technical monitor.

The authors wish to thank Dr. Stephen Cumblidge for his technical contributions and support of beam modeling for phased-array inspection.

The authors wish to thank Jack Lareau for his technical guidance for the mockup notch designs.

In addition, the authors express their sincere gratitude to Guy Maes and Patrick Tremblay at ZETEC, Inc. for their willingness and ongoing engineering support with phased-array system functional and operational issues, as well as their guidance and input regarding phased-array probe design and manufacture.

\section{NOMENCLATURE}

BMV bare metal visual

$\mathrm{dB}$ decibels

CRDM control rod drive mechanism

EDM electric discharge machining

EPRI Electric Power Research Institute

ID inner diameter 


$\begin{array}{ll}\text { LN } & \text { liquid nitrogen } \\ \text { NDE } & \text { nondestructive examination } \\ \text { NRC } & \text { U.S. Nuclear Regulatory Commission } \\ \text { OD } & \text { outer diameter } \\ \text { PA } & \text { phased array } \\ \text { PA-UT } & \text { phased array ultrasonic testing } \\ \text { PE } & \text { pulse echo } \\ \text { PNNL } & \text { Pacific Northwest National Laboratory } \\ \text { PWR } & \text { pressurized water reactor } \\ \text { PWSCC } & \text { primary water stress corrosion cracking } \\ \text { RVH } & \text { reactor vessel head }\end{array}$

\section{REFERENCES}

[1] Gorman, J., Hunt, S., Riccardella, P., and White, G.A., 2009, “PWR Reactor Vessel Alloy 600 Issues,” Companion Guide to the ASME Boiler and Pressure Vessel Code, Volume 3, Third Edition, Rao, KR, Chapter 44

[2] Integration of NDE Reliability and Fracture Mechanics, NUREG/CR 1696-V1, March 1981

[3] Howell, A.T. Davis-Besse Reactor Vessel Head Degradation Lessons-Learned Task Force Report, NRC/EDO, ML022760172, 09/30/2002, Technical Report

[4] Cumblidge, S. E., Doctor, S. R., Schuster, G. J., Harris Jr., R. V., Crawford, S. L., Seffens, R. J., Toloczko, M. B., and Bruemmer, S. M., 2009, "Nondestructive and Destructive Examination Studies on Removed-from-Service Control Rod Drive Mechanism Penetrations," NUREG/CR-6996, PNNL-18372, U.S. Nuclear Regulatory Commission, Washington, D.C.

[5] Lang TA. 2003. "Significant Corrosion of the Davis-Besse Nuclear Reactor Pressure Vessel Head.” In ASME 2003 Pressure Vessels and Piping Conference (PVP2003), July 20-24, 2003, Cleveland, Ohio. American Society of Mechanical Engineers, New York.

[6] Clark, A. F., 1968, "Low Temperature Thermal Expansion of Some Metallic Alloys," Cryogenics, 8(5), 282-289.

[7] Marquardt, E. D., Le, J. P., and Radebaugh, R., 2002, "Cryogenic Material Properties Database," Cryocoolers 11, 11th International Cryocooler Conference, Ross RG ed. Springer US, pp. 681-687. 